\title{
Correlations between Meteorological Indicators, Air Quality and the COVID-19 Pandemic in 12 Cities across China
}

\author{
Huiying Huang ${ }^{1} \cdot$ Xiuji Liang ${ }^{2} \cdot$ Jingxiu Huang $^{3} \cdot$ Zhaohu Yuan $^{1} \cdot$ Handong Ouyang $^{3} \cdot$ Yaming Wei $^{1} \cdot$ Xiaohui Bai $^{4}$
}

Received: 18 May 2020 / Accepted: 4 October 2020

(C) Springer Nature Switzerland AG 2020, corrected publication 2022

\begin{abstract}
Background COVID-19 is a global pandemic. The purpose of this study is to explore correlations between the novel coronavirus (COVID-19) and meteorological indicators from cities across China.

Methods We collected daily data of the cumulative number of infected, recovered and death cases, and the meteorological indicators including average temperature, wind speed, relative humidity, precipitation and air quality index (AQI) from 12 cities in China during the period of Jan 23 to Feb 22, 2020. Correlation tests were chosen for data analysis.

Results The average temperature and AQI showed significant association with the mortality rate of COVID-19. The mortality rate was not correlated with wind speed, relative humidity or precipitation. Meanwhile, higher average temperatures and more precipitation were beneficial for the recovery rate of COVID-19, but the recovery rate was not correlated with wind speed, relative humidity or AQI.

Conclusions Our study provides a new basis for correlations between COVID-19, meteorological indicators and air quality index, which can help authorities to combat COVID-19.
\end{abstract}

Keywords COVID-19 $\cdot$ Average temperature $\cdot$ Wind speed $\cdot$ Relative humidity $\cdot$ Precipitation $\cdot$ Air quality index

\section{Introduction}

On December 31, 2019 a type of pneumonia of an unknown cause was detected in Wuhan, China and reported to the WHO

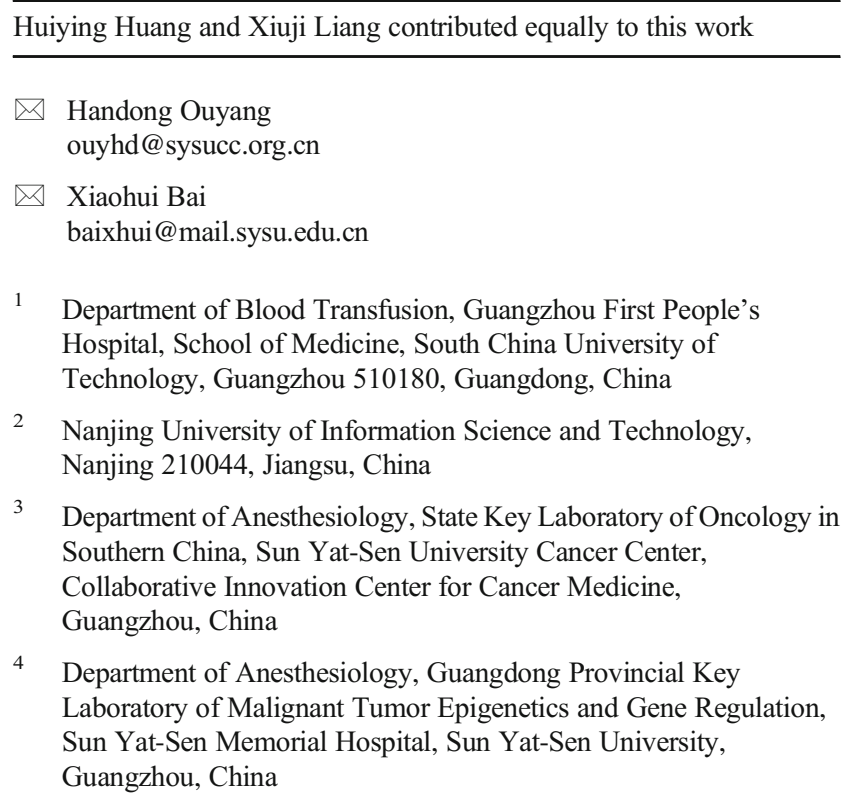

1 Department of Blood Transfusion, Guangzhou First People's Hospital, School of Medicine, South China University of Technology, Guangzhou 510180, Guangdong, China

2 Nanjing University of Information Science and Technology, Nanjing 210044, Jiangsu, China

3 Department of Anesthesiology, State Key Laboratory of Oncology in Southern China, Sun Yat-Sen University Cancer Center, Collaborative Innovation Center for Cancer Medicine, Guangzhou, China

4 Department of Anesthesiology, Guangdong Provincial Key Laboratory of Malignant Tumor Epigenetics and Gene Regulation, Sun Yat-Sen Memorial Hospital, Sun Yat-Sen University, Guangzhou, China 
now, and regrettably, no specifically proven vaccines or treatments for COVID-19 exist, although human trials are ongoing [9-11]. By September 22, 2020, SARS-CoV-2 had caused 90,898 infections with 4,744 deaths in China, and $31,362,666$ infections and 966,272 deaths in 205 countries around the world, with the worldwide situation still not optimistic. As such, the importance of SARS-CoV-2 studies requires little more justification, in particular, the epidemiological and virological studies of COVID-19 that will help us to control it more effectively.

It is believed that the COVID-19 epidemic is related to many factors, including meteorological, geographical, biological, environmental and behavioral factors. All of these factors need to be considered in order to estimate risk level areas and for the prevention and control of the disease by public health organizations to surveil and contain it more successfully [12-14].

Previous studies have supported an epidemiological hypothesis that weather conditions may affect the survival and spread of droplet-mediated viral diseases. It has been documented that the temperature and its variations might have affected the 2003 SARS outbreak [15]. Meteorological factors played an important role in the outbreak of COVID-19 in China and the temperature may be useful in predicting the potential spread of COVID-19 in other countries [16]. Daily COVID-19 death counts were positively associated with the diurnal temperature range, but had a negative association with relative humidity from January 20, 2020 to February 29, 2020 in Wuhan [17]. The effects of low temperatures, a mild diurnal temperature range and low humidity was said to increase the spread of COVID-19, conversely, it was said the warmer weather in China from January 20 to March 2020 minimized its spread [18-20]. A recent meta-analysis showed that the overall intensity of the COVID-19 epidemic in China reduced slightly following the days with higher temperatures [16]. However, other researchers who have investigated the effects of temperature, humidity, precipitation, and wind speed on the rate of COVID-19's spread in China between January 23 to March 1, 2020 found that the doubling time of the number of cases was positively correlated with temperature, and negatively correlated with humidity, and estimated that weather variables could only explain $18 \%$ of the variation in the disease doubling time [21]. The maximum temperature and normal temperature were positively associated with incidence rate of daily COVID-19 cases in Oslo as people disobeyed the government's "stay-home" rules under the warmer weather, whereas precipitation was negatively associated [22]. The association between COVID-19 and the average temperature and average relative humidity across the provinces was inconsistent in China [23]. Since then, the correlation between meteorological indicators and the COVID-19 epidemic are still uncertain. Much more research is required to provide more precise conclusions.
In addition, many of these studies only considered meteorological factors, which limits the reliability of their results. We also acknowledge that air quality index (AQI) is an important factor for many respiratory infectious diseases, as bad air quality led to increased mortality in the city of Wuhan [24]. The weather can also affect the AQI directly, as rainfall reduces atmospheric pollutants. Moreover, COVID-19 can be partly transmitted by aerosols [25], in which there is a close relationship between AQI and aerosols [26]. Yet, no studies have explored the interaction between meteorological factors and AQI with new COVID-19 cases, the mortality rate and recovered rates in the early stages of the population migration control in China. In this study, we chose 12 cities across China to investigate the relationship between the meteorological factors and AQI with the epidemiology of COVID-19 from January 23 to February 22, 2020. We attempt to clarify the roles of these two indicators on the spread of COVID-19 in China.

\section{Methods}

\section{Data collection}

Twelve cities: Guangzhou, Chongqing, Hefei, Shanghai, Beijing, Harbin, Xinyang, Changsha, Nanchang, Xianning, Shenzhen, and Wenzhou were chosen as the study objects, due to their representative spread around China, and because they are first-tier populous Chinese cities. We obtained the official daily reported total number of infected cases, recovered cases and deaths in the 12 cities during the period from January 23 to February 22, 2020. We also collected the data for meteorological indicators including average temperature, wind speed, relative humidity, and precipitation. Data sources: https://rda.ucar.edu/datasets/ds083.2/index.html (NCEP FNL Operational Model Global Tropospheric Analyses). The AQI was based on the levels of six atmospheric pollutants, namely, sulfur dioxide $\left(\mathrm{SO}_{2}\right)$, nitrogen dioxide $\left(\mathrm{NO}_{2}\right)$, suspended particulates smaller than $10 \mu \mathrm{m}$ in aerodynamic diameter $\left(\mathrm{PM}_{10}\right)$, suspended particulates smaller than $2.5 \mu \mathrm{m}$ in aerodynamic diameter $\left(\mathrm{PM}_{2.5}\right)$, carbon nmonoxide $(\mathrm{CO})$, and ozone $\left(\mathrm{O}_{3}\right)$ measured at the monitoring stations throughout each city in China. The AQI was calculated via methods described elsewhere [27] and the data for the six related atmospheric pollutants were from https://www. cnemc.cn/. AQI was classified via the Ambient Air Quality Standards (GB3095-2012) and the Technical Regulations on Ambient Air Quality Index (HJ 633-2012). Wuhan was excluded from this study as the number of COVID-19 patients in Wuhan were dozens of times higher than other cities, and in some cases, hundreds of times higher. Such huge gap in cases between Wuhan and other cities makes Wuhan a more 
suitable independent research project as its inclusion would obfuscate the statistical analyses.

\section{Statistical analysis}

All data was input with EXCEL 2016, following statistics analysis using SPSS 21.0. One way ANOVA was used to determine whether there were differences among the meteorological factors of average temperature, wind speed, relative humidity, precipitation and AQI among the 12 specified cities. Multiple regression correlation analysis was used to determine the correlation between average temperature, wind speed, relative humidity, precipitation, AQI and mortality, recovered, and new case incidence rates. The recovered and morbidity rates in the cities were defined as below:

Recovered rate $=$ number of recovered cases with COVID19 / number of total infected cases $\times 100 \%$;

Morbidity rate $=$ number of deaths by COVID-19 $/$ number of total infected cases $\times 100 \%$. At the test level, a $P<0.05$ was considered statistically significant.

\section{Results}

\section{Descriptive analysis}

There were significant distributional differences in daily meteorological factors, including average temperature, wind speed, relative humidity, precipitation and AQI in China from Jun 23 to Feb 22, 2020 across the 12 cities. The average temperatures in these cities (except Harbin) were higher than the national average temperature of -2.25 . The data indicated that the higher the latitude the lower the average temperature in China during the studied period (Fig. 1a, Table 1). The wind speeds varied greatly among the 12 cities. The average wind speeds are shown in Fig. 1.b The cities of Harbin, Shanghai, Wenzhou, Guangzhou and Shenzhen, displayed an average wind speed of more than $3 \mathrm{~m} / \mathrm{s}$ from Jan 24 to Jan 25, Feb 5 to Feb 6, and Feb 14 to Feb 16 (Fig. 1b, Table 1).

The relative humidity and precipitation in the 12 cities presented significant distributional differences (Fig. 1c, d, Table 1). Heavy snow and rains appeared in large areas in China from Feb 14 to Feb 17. Precipitation reached $10 \sim$ $25 \mathrm{~mm}$ in Chongqing and Xinyang, 25 50 $\mathrm{mm}$ in Hefei, Shanghai, Changsha, Nanchang, Xianning and Shenzhen, and more than $50 \mathrm{~mm}$ in Guangzhou. The AQI was poor in Hefei, Shanghai, Changsha, Nanchang, Xianning, and Shenzhen in February, while severe air pollution (AQI > 200) lasted for three days in Beijing (Fig. 1e, Table 1). OneWay ANOVA analysis showed significant differences in the meteorological factors including average temperature, wind speed, relative humidity, precipitation and AQI among the 12 cities (Table $1, P<0.01$ ) (Fig. 2).

\section{Correlation analysis}

Multiple regression correlation analysis showed that:

1) The mortality rate caused by COVID-19 was negatively correlated with the average temperature, with a correlation coefficient of $-0.711(\mathrm{r}=-0.711, P<0.05)$. However, the COVID-19 mortality rate was positively associated with AQI, with a correlation coefficient of $0.702(\mathrm{r}=$ $0.702, P<0.05)$. This indicates that the mortality rate

Table 1 The meteorological factors from 12 cities in China

\begin{tabular}{llllll}
\hline City & Average temperature $\left({ }^{0} \mathrm{C}\right)$ & Wind speed $(\mathrm{m} / \mathrm{s})$ & Relative humidity $(\%)$ & Precipitation $(\mathrm{mm})$ & Air quality index \\
\hline Guangzhou & $15.48 \pm 3.54$ & $1.88 \pm 0.81$ & $65.10 \pm 17.40$ & $4.85 \pm 13.01$ & $59.13 \pm 9.86$ \\
Chongqing & $9.69 \pm 1.94$ & $1.51 \pm 0.55$ & $77.61 \pm 10.76$ & $0.90 \pm 1.40$ & $68.97 \pm 13.42$ \\
Hefei & $6.23 \pm 3.26$ & $1.88 \pm 0.61$ & $76.96 \pm 16.46$ & $1.70 \pm 5.06$ & $69.42 \pm 15.58$ \\
Shanghai & $7.40 \pm 3.00$ & $1.85 \pm 0.57$ & $72.81 \pm 17.52$ & $4.22 \pm 7.66$ & $56.16 \pm 13.09$ \\
Beijing & $-0.26 \pm 2.87$ & $1.68 \pm 0.83$ & $58.77 \pm 15.92$ & $0.11 \pm 0.41$ & $87.10 \pm 18.67$ \\
Harbin & $-13.82 \pm 6.07$ & $1.87 \pm 0.67$ & $68.58 \pm 8.23$ & $1.11 \pm 2.70$ & $74.61 \pm 14.13$ \\
Xinyang & $7.41 \pm 3.90$ & $1.71 \pm 0.63$ & $69.05 \pm 18.93$ & $5.71 \pm 9.51$ & $81.39 \pm 16.61$ \\
Changsha & $7.98 \pm 3.65$ & $1.81 \pm 1.01$ & $75.43 \pm 18.97$ & $6.93 \pm 14.53$ & $64.52 \pm 14.95$ \\
Nanchang & $8.96 \pm 3.11$ & $1.24 \pm 0.49$ & $75.85 \pm 16.06$ & $4.23 \pm 7.32$ & $60.26 \pm 8.29$ \\
Xianning & $6.80 \pm 3.24$ & $1.74 \pm 0.68$ & $74.68 \pm 11.60$ & $3.00 \pm 5.99$ & $59.00 \pm 11.38$ \\
Shenzhen & $16.74 \pm 3.00$ & $2.50 \pm 0.57$ & $68.54 \pm 16.23$ & $1.88 \pm 4.77$ & $50.35 \pm 12.40$ \\
Wenzhou & $9.86 \pm 2.46$ & $1.45 \pm 0.62$ & $72.77 \pm 15.38$ & 2.41 & $52.58 \pm 11.72$ \\
$F$ & 115.63 & 5.84 & 4.02 & $<0.01$ & 12.38 \\
$P$ & $<0.01$ & $<0.01$ & $<0.01$ & $<0.01$ & \\
\hline
\end{tabular}

Data were shown as mean $\pm \mathrm{SD}$ 

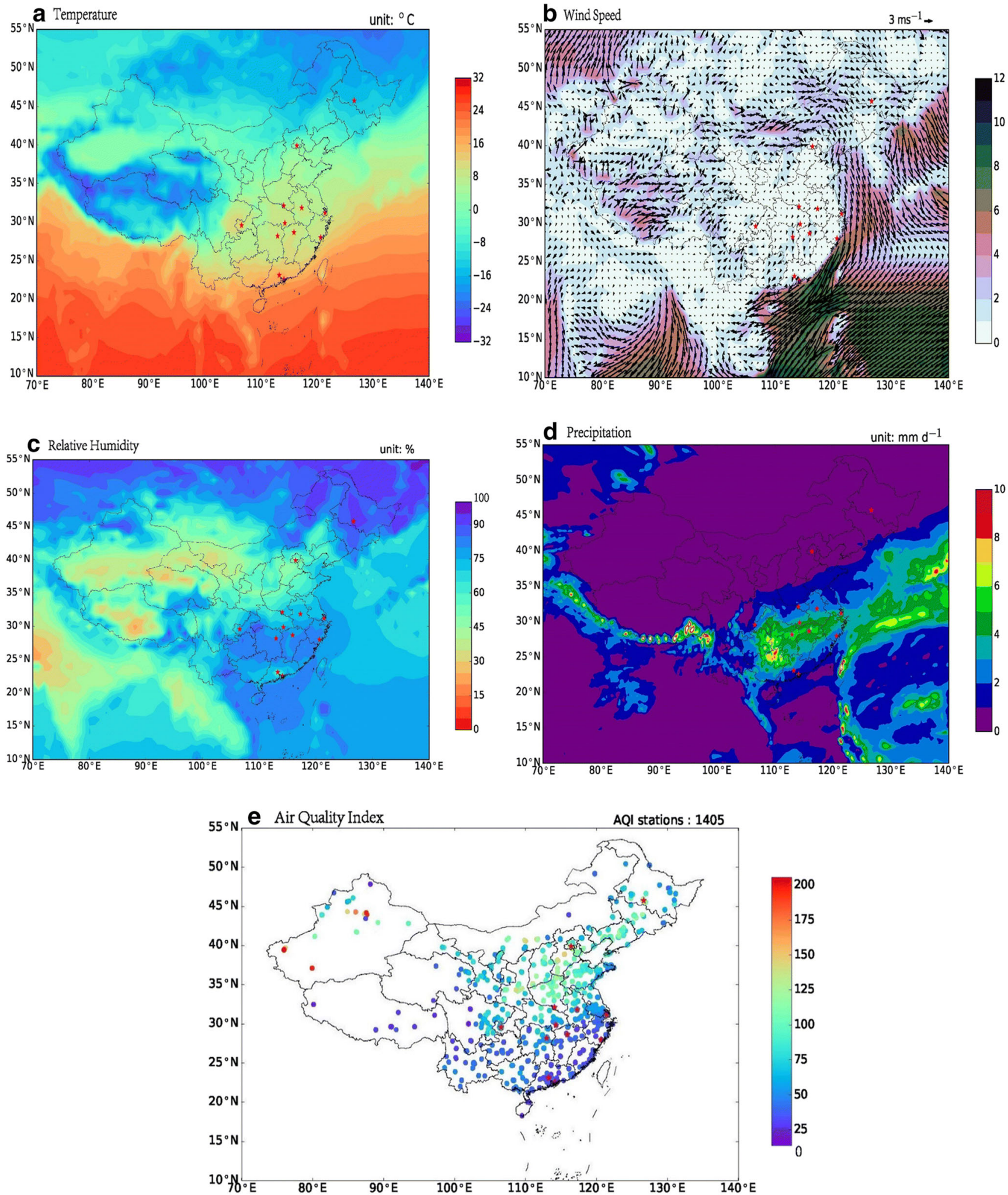

Fig. 1 a-e Meteorological map from Jan 23 to Feb 22. a Temperature, b $3 \mathrm{~m} / \mathrm{s}$ Wind Speed, c Relative Humidity, d Precipitation, e Air Quality Index. Average temperature, Wind Speed, Relative humidity, and

may rise when the average temperature decreases and the AQI increases. There was no correlation between
Precipitation data sources: https://rda.ucar.edu/datasets/ds083.2/index. html (NCEP FNL Operational Model Global Tropospheric Analyses). Air Quality Index data sources: https://www.cnemc.cn/

mortality and wind speed $(\mathrm{r}=0.118, P=0.728)$, no correlation between mortality rate and relative humidity $(\mathrm{r}=-$ 
Fig. 2 a-c Epidemiological overview of COVID-19 in the 12 cities. a Daily data of new cases in the 12 cities, China; b Daily data of recovered cases in the 12 cities, China; c Daily data of death cases in the 12 cities, China
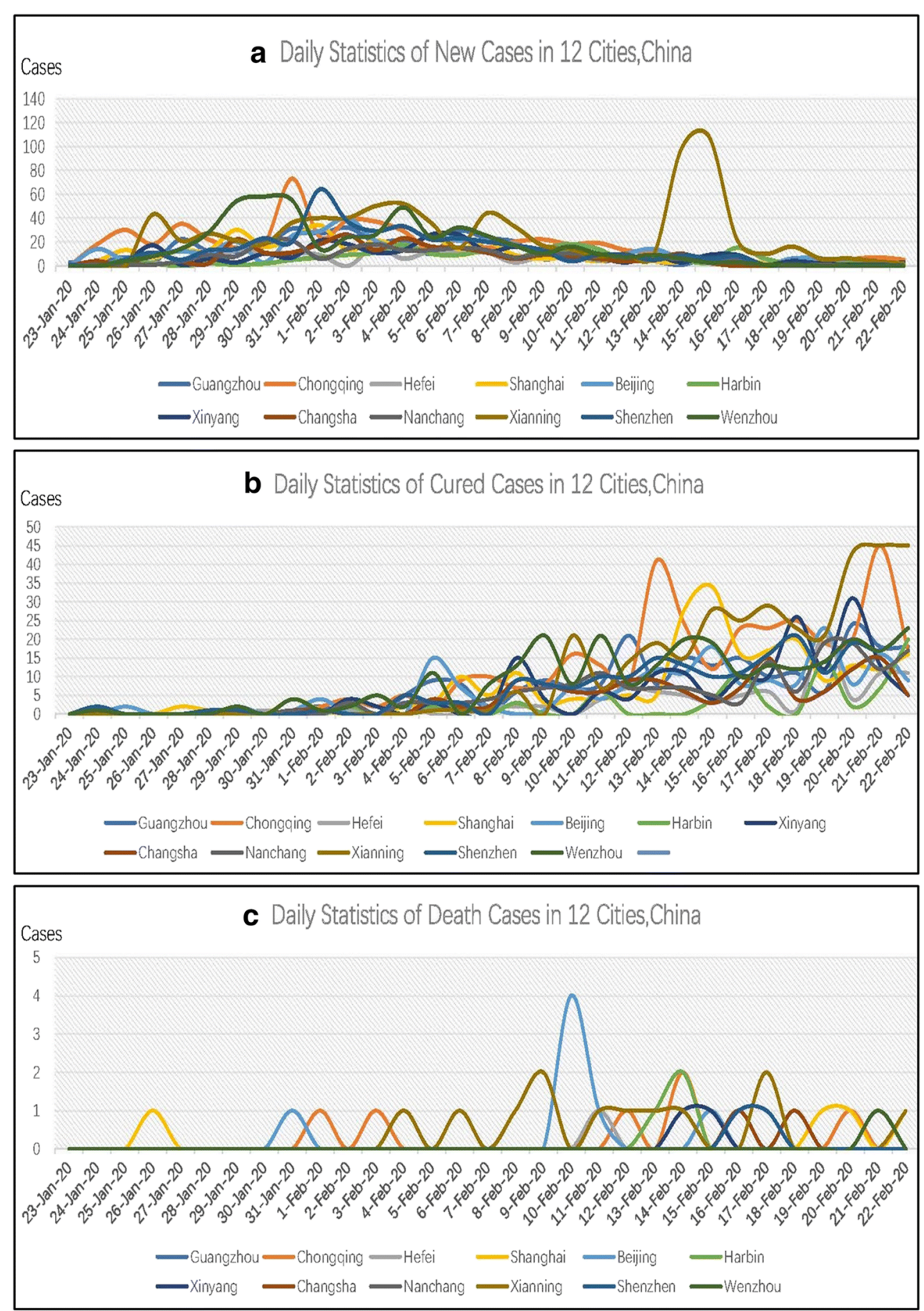

$0.344, P=0.301$ ), and no correlation between the mortality rate and precipitation $(\mathrm{r}=-0.566, P=0.070)$.

2) The recovered rate of COVID-19 was correlated with average temperature and precipitation $(P<0.05)$ with correlation coefficients of 0.629 and 0.652 , respectively. This indicates that the recovered rate may rise when the average temperature and precipitation increase. There was no correlation between the recovered rate and wind speed $(\mathrm{r}=-0.342, P=0.303)$, no correlation between the recovered rate and relative humidity $(\mathrm{r}=0.424, P=$ 0.193 ) and no correlation between the recovered rate and AQI $(\mathrm{r}=0.423, P=0.195)$.

3) The new case incidence rate was not correlated with average temperature, wind speed, relative humidity, AQI or precipitation $(\mathrm{r}=0.070, P=0.837$ for average temperature, $\mathrm{r}=-0.165, P=0.838$ for wind speed; $\mathrm{r}=0.380, P=$ 0.248 for relative humidity; $\mathrm{r}=-0.179, P=0.589$ for AQI; $\mathrm{r}=-0.229, P=0.498$ for precipitation, respectively). The 
results show there is no correlation between these climatic factors and AQI with new incidence across these 12 cities;

4) The equation of regression presents as:

Mortality rate $=-0.031 \times$ temperature $+0.026 \times \mathrm{AQI}$ $0.682 ; \mathrm{R}^{2}=0.586 ; \mathrm{F}=5.667 ; P=0.029$;

Recovery rate $=0.491 \times$ tepmmperature $+2.002 \times$ precipitation $+47.150 ; \mathrm{R}^{2}=0.566 ; \mathrm{F}=4.856 ; P=0.042$.

\section{Discussion}

The total number of infected patients was 76,936 in China, with 22,888 recovered cases and 2,442 dead up to February 22, 2020. This present study explored correlations between meteorological indicators and AQI during the COVID-19 epidemic across 12 cities under China's population migration control measures. Our results show that the mortality rate of COVID-19 is negatively correlated with average temperature, but positively correlated with AQI. The recovered rate of COVID-19 was both positively correlated with the average temperature and precipitation from January 23, 2020 to February 22, 2020 in the 12 Chinese cities. There was no correlation between meteorological factors and AQI with new COVID-19 cases.

As is well-known, viruses depend on their hosts for replication and survival. Viruses can also variate during meteorological changes [28], which can cause outbreaks of new diseases, such as SARS-CoV and MERS. The COVID-19 outbreak was reported in winter. Thus, the respiratory systems of the population were more susceptible in the cold environments due to its uncontrolled spread. Some studies on SARS-CoV showed that the outbreak was correlated with temperature $[15,29]$. The study of MERS also showed that the activity of the virus decreased in hot and humid environments [30]. In China, in regards to SARS-CoV-2 the average temperature was still relatively low even when spring came. Meanwhile, severe air pollution occurred in February in Beijing, with an AQI > 200, which was partly correlated with the mortality of COVID-19.

Such low temperatures and transitory air pollution were not beneficial for the degeneration and inactivation of SARSCoV-2 as mortality increased. Researchers have claimed that SARS-CoV-2 is less transmissible at higher temperatures [31]. These studies claimed that auto-degeneration of viruses was more common at a higher temperature [32]. The mechanisms include 1) higher temperatures may denature capsid proteins and glycoprotein spikes of enveloped viruses, which inhibit the attachment ability of viruses to host cells; 2 ) higher temperatures may damage the enzymes needed for virus duplication, which inhibit viral uncoating [32]. Thus, the incidence rate of new cases might rise as it turns to autumn and winter in the southern hemisphere. Although higher temperatures benefit the degeneration and inactivation of the COVID-19 virus, special effective public health measures are still necessary for preventing its spread.

Aerosol transmission of SARS-CoV-2 is plausible, since the virus can remain infectious in aerosols for hours and on surfaces for days (depending on the inoculum shed) [25]. Aerosols can be partly influenced by precipitation [33]. The wet scavenging of precipitation greatly reduces aerosols by scouring pre-existing particles [34]. The inhalable particles that settle down can reduce the quantity of SARS-CoV-2 floating in the air [35]. This is also beneficial for the recovery of COVID-19.

The national public health interventions in China played a key role in controlling the COVID-19 pandemic, and the meteorological conditions are not the only factors influencing the disease trends. This present study revealed that meteorological factors, such as average temperature, precipitation, AQI are correlated with COVID-19. However, these are not the only factors to affect the trends of the outbreak.

As the COVID-19 pandemic continues, the unexpected particulate matter (PM) elevation has potentially profound implications for the airborne transmission of the virus [36]. A new emerging study shows plausible virus transmission via aerosols in populous areas [37]. In our results, AQI was positively related with the mortality rate. We speculate that exposure to high levels of six atmospheric pollutants $\left(\mathrm{SO}_{2}, \mathrm{NO}_{2}\right.$, $\mathrm{PM}_{10}, \mathrm{PM}_{2.5}, \mathrm{CO}, \mathrm{O}_{3}$ ) may cause adverse effects on the respiratory and cardiovascular systems, and possibly increase the fatality rate of COVID-19 [36, 38], as COVID-19's incidence was enhanced by increased AQI (decreased air quality), particularly $\mathrm{PM}_{2.5}$, and $\mathrm{NO}_{2}$ [39].

The inhalable particles induce injury to the endothelial cell membrane, which creates an inflammatory reaction and coagulation abnormalities, such as blood coagulation, thrombosis, arrhythmia, systematic inflammatory reaction and atherosclerosis $[13,14]$. The inhalable particles can react with different immune cells, which can injure the structure and functions of the immune system. Especially, the inhalable particulate matter $\mathrm{PM}_{2.5}$, as evidence shows that the mortality of COVID-19 could increase by $8 \%$ when $\mathrm{PM}_{2.5}$ increases by $1 \mu \mathrm{g} / \mathrm{m}^{3}$ [40]. Due to its relatively smaller size, $\mathrm{PM}_{2.5}$ is more pernicious as it can penetrate the respiratory tract and reach the alveoli directly [41]. $\mathrm{PM}_{2.5}$ can disrupt the human respiratory barrier's integrity [42]. Thus, dysfunctional respiratory barriers are more likely to expose deeper respiratory tissue to foreign pathogens. However, more detailed studies on the meteorological factors and AQI are warranted in order to help public health departments better manage the pandemic. In particular, studies with a wider geographical spread and over a longer time period.

Our study has some limitations. First, there were only twelve cities in this analysis, which might result in some deviation from the exact effect of ambient pollution and meteorological parameters on SARS-CoV-2 transmission. Second, 
the study period is relatively short compared with other epidemiological studies. In a future study, we will collect more data from multiple cities and areas to validate the results from this study. Third, only four meteorological data and AQI data were collected.

In conclusion, our work provides some useful information about the epidemiology of COIVD-19 during the early period of the outbreak in China. The COVID-19 mortality rate was positively correlated with $\mathrm{AQI}$ and negatively correlated with average temperature. The COVID-19 recovered rate was positively correlated with average temperature and precipitation. Our results may help not only China, but also other countries as the seasons change and newly considered approaches are needed to continue to mitigate the spread of the virus.

Author's contributions Conceptualization: [Yaming Wei], [Handong Ouyang] [Xiaohui Bai]; Methodology: [Huiying Huang], [Jingxiu Huang]; Formal analysis and investigation: [Huiying Huang], [Jingxiu Huang], [Xiuji Liang], [Zhaohu Yuan]; Writing-original draft preparation: [Huiying Huang], [Jingxiu Huang]; Writing- review and editing: [Huiying Huang], [Jingxiu Huang], [Yaming Wei], [Handong Ouyang]; Supervision: [Handong Ouyang], [Xiaohui Bai].

\section{Compliance with ethical standards}

Conflicts of interest The authors declared that they have no conflicts of interest to this work.

Data transparency All authors are sure that all data and materials as well as software applications and custom codes support their published claims and comply with field standards.

\section{References}

1. Wu F, Zhao S, Yu B, Chen YM, Wang W, Song ZG, et al. A new coronavirus associated with human respiratory disease in China. Nature. 2020;579(7798):265-9. https://doi.org/10.1038/s41586020-2008-3.

2. Chen N, Zhou M, Dong X, Qu J, Gong F, Han Y, et al. Epidemiological and clinical characteristics of 99 cases of 2019 novel coronavirus pneumonia in Wuhan, China: a descriptive study. Lancet. 2020;395(10223):507-13. https://doi.org/10.1016/ S0140-6736(20)30211-7.

3. Holshue ML, DeBolt C, Lindquist S, Lofy KH, Wiesman J, Bruce $\mathrm{H}$, et al. First Case of 2019 Novel Coronavirus in the United States. The New England journal of medicine. 2020;382(10):929-36. https://doi.org/10.1056/NEJMoa2001191.

4. Faridi S, Niazi S, Sadeghi K, Naddafi K, Yavarian J, Shamsipour $\mathrm{M}$, et al. A field indoor air measurement of SARS-CoV-2 in the patient rooms of the largest hospital in Iran. Sci Total Environ. 2020;725:138401. https://doi.org/10.1016/j.scitotenv.2020. 138401.

5. Coronaviridae Study Group of the International Committee on Taxonomy of V. The species Severe acute respiratory syndromerelated coronavirus: classifying 2019-nCoV and naming it SARSCoV-2. Nat Microbiol. 2020;5(4):536-44. https://doi.org/10.1038/ s41564-020-0695-z.

6. Lai CC, Shih TP, Ko WC, Tang HJ, Hsueh PR. Severe acute respiratory syndrome coronavirus 2 (SARS-CoV-2) and coronavirus disease-2019 (COVID-19): the epidemic and the challenges. Int J Antimicrob Agents. 2020;55(3):105924. https://doi.org/10.1016/j. ijantimicag.2020.105924.

7. Wu C, Chen X, Cai Y, Xia J, Zhou X, Xu S, et al. Risk factors associated with acute respiratory distress syndrome and death in patients with coronavirus disease 2019 pneumonia in Wuhan, China. JAMA Intern Med. 2020. https://doi.org/10.1001/ jamainternmed.2020.0994.

8. Yang Z, Zeng Z, Wang K, Wong SS, Liang W, Zanin M, et al. Modified SEIR and AI prediction of the epidemics trend of COVID-19 in China under public health interventions. J Thorac Dis. 2020;12(3):165-74. https://doi.org/10.21037/jtd.2020.02.64.

9. Folegatti PM, Ewer KJ, Aley PK, Angus B, Becker S, BelijRammerstorfer $\mathrm{S}$, et al. Safety and immunogenicity of the ChAdOx1 nCoV-19 vaccine against SARS-CoV-2: a preliminary report of a phase $1 / 2$, single-blind, randomised controlled trial. Lancet. 2020;396(10249):467-78. https://doi.org/10.1016/S01406736(20)31604-4.

10. Mahase E. Covid-19: Oxford researchers halt vaccine trial while adverse reaction is investigated. BMJ. 2020;370:m3525. https:// doi.org/10.1136/bmj.m3525.

11. Zhu FC, Li YH, Guan XH, Hou LH, Wang WJ, Li JX, et al. Safety, tolerability, and immunogenicity of a recombinant adenovirus type5 vectored COVID-19 vaccine: a dose-escalation, open-label, nonrandomised, first-in-human trial. Lancet. 2020;395(10240):184554. https://doi.org/10.1016/S0140-6736(20)31208-3.

12. Sajadi MM, Habibzadeh P, Vintzileos A, Shokouhi S, MirallesWilhelm F, Amoroso A. Temperature, humidity, and latitude analysis to estimate potential spread and seasonality of coronavirus disease 2019 (COVID-19). JAMA Netw Open. 2020;3(6): e2011834. https://doi.org/10.1001/jamanetworkopen.2020.11834.

13. Yuki K, Fujiogi M, Koutsogiannaki S. COVID-19 pathophysiology: a review. Clin Immunol. 2020;215:108427. https://doi.org/10. 1016/j.clim.2020.108427.

14. Dhama K, Khan S, Tiwari R, Sircar S, Bhat S, Malik YS, et al. Coronavirus disease 2019-COVID-19. Clin Microbiol Rev. 2020;33(4). https://doi.org/10.1128/CMR.00028-20.

15. Tan J, Mu L, Huang J, Yu S, Chen B, Yin J. An initial investigation of the association between the SARS outbreak and weather: with the view of the environmental temperature and its variation. $\mathrm{J}$ Epidemiol Community Health. 2005;59(3):186-92. https://doi. org/10.1136/jech.2004.020180.

16. Shi P, Dong Y, Yan H, Zhao C, Li X, Liu W, et al. Impact of temperature on the dynamics of the COVID-19 outbreak in China. Sci Total Environ. 2020;728:138890. https://doi.org/10. 1016/j.scitotenv.2020.138890.

17. Ma Y, Zhao Y, Liu J, He X, Wang B, Fu S, et al. Effects of temperature variation and humidity on the death of COVID-19 in Wuhan. China Sci Total Environ. 2020;724:138226. https://doi. org/10.1016/j.scitotenv.2020.138226.

18. Poirier C, Luo W, Majumder MS, Liu D, Mandl K, Mooring T, et al. The role of environmental factors on transmission rates of the covid-19 outbreak: an initial assessment in two spatial scales. SSRN. 2020:3552677. https://doi.org/10.2139/ssrn.3552677.

19. Guo XJ, Zhang H, Zeng YP. Transmissibility of COVID-19 in 11 major cities in China and its association with temperature and humidity in Beijing, Shanghai, Guangzhou, and Chengdu. Infect Dis Poverty. 2020;9(1):87. https://doi.org/10.1186/s40249-020-00708-0.

20. Liu J, Zhou J, Yao J, Zhang X, Li L, Xu X, et al. Impact of meteorological factors on the COVID-19 transmission: a multi-city study in China. Sci Total Environ. 2020;726:138513. https://doi. org/10.1016/j.scitotenv.2020.138513.

21. Oliveiros B, Caramelo L, Ferreira N, Caramelo F. Role of temperature and humidity in the modulation of the doubling time of COVID-19 cases. MedRxiv 2020.https://doi.org/10.1101/2020.03. 05.20031872 . 
22. Menebo MM. Temperature and precipitation associate with Covid19 new daily cases: A correlation study between weather and Covid-19 pandemic in Oslo. Norway Sci Total Environ. 2020;737:139659. https://doi.org/10.1016/j.scitotenv.2020. 139659.

23. Qi H, Xiao S, Shi R, Ward MP, Chen Y, Tu W, et al. COVID-19 transmission in Mainland China is associated with temperature and humidity: a time-series analysis. Sci Total Environ. 2020;728: 138778. https://doi.org/10.1016/j.scitotenv.2020.138778.

24. Fareed Z, Iqbal N, Shahzad F, Shah SGM, Zulfiqar B, Shahzad K, et al. Co-variance nexus between COVID-19 mortality, humidity, and air quality index in Wuhan, China: New insights from partial and multiple wavelet coherence. Air Qual Atmos Health. 2020:110. https://doi.org/10.1007/s11869-020-00847-1.

25. van Doremalen N, Bushmaker T, Morris DH, Holbrook MG, Gamble A, Williamson BN, et al. Aerosol and surface stability of SARS-CoV-2 as compared with SARS-CoV-1. The New England journal of medicine. 2020;382(16):1564-7. https://doi.org/10. 1056/NEJMc2004973.

26. Jung J, Souri AH, Wong DC, Lee S, Jeon W, Kim J, et al. The impact of the direct effect of aerosols on meteorology and air quality using aerosol optical depth assimilation during the KORUS-AQ campaign. J Geophys Res Atmos. 2019;124(14):8303-19. https:// doi.org/10.1029/2019JD030641.

27. Yousefian F, Faridi S, Azimi F, Aghaei M, Shamsipour M, Yaghmaeian K, et al. Temporal variations of ambient air pollutants and meteorological influences on their concentrations in Tehran during 2012-2017. Sci Rep. 2020;10(1):292. https://doi.org/10. 1038/s41598-019-56578-6.

28. Wu X, Lu Y, Zhou S, Chen L, Xu B. Impact of climate change on human infectious diseases: empirical evidence and human adaptation. Environ Int. 2016;86:14-23. https://doi.org/10.1016/j.envint. 2015.09.007.

29. Lin K, Yee-Tak Fong D, Zhu B, Karlberg J. Environmental factors on the SARS epidemic: air temperature, passage of time and multiplicative effect of hospital infection. Epidemiol Infect. 2006;134(2):223-30. https://doi.org/10.1017/S0950268805005054.

30. van Doremalen N, Bushmaker T, Munster VJ. Stability of Middle East respiratory syndrome coronavirus (MERS-CoV) under different environmental conditions. Euro Surveill. 2013;18(38). https:// doi.org/10.2807/1560-7917.es2013.18.38.20590.

31. Demongeot J, Flet-Berliac Y, Seligmann H. Temperature decreases spread parameters of the new Covid-19 case dynamics. Biology (Basel). 2020;9(5). https://doi.org/10.3390/biology9050094.

32. Chen P, Shakhnovich EI. Thermal adaptation of viruses and bacteria. Biophys J. 2010;98(7):1109-18. https://doi.org/10.1016/j.bpj. 2009.11.048
33. Dadashazar H, Ma L, Sorooshian A. Sources of pollution and interrelationships between aerosol and precipitation chemistry at a central California site. Sci Total Environ. 2019;651(Pt 2):177687. https://doi.org/10.1016/j.scitotenv.2018.10.086.

34. Duan J, Wang Y, Xie X, Li M, Tao J, Wu Y, et al. Influence of pollutants on activity of aerosol cloud condensation nuclei (CCN) during pollution and post-rain periods in Guangzhou, southern China. Sci Total Environ. 2018;642:1008-19. https://doi.org/10. 1016/j.scitotenv.2018.06.053.

35. Wang J, Du G. COVID-19 may transmit through aerosol. Ir J Med Sci. 2020. https://doi.org/10.1007/s11845-020-02218-2.

36. Zhang R, Li Y, Zhang AL, Wang Y, Molina MJ. Identifying airborne transmission as the dominant route for the spread of COVID19. Proc Natl Acad Sci U S A. 2020;117(26):14857-63. https://doi. org/10.1073/pnas.2009637117.

37. Liu Y, Ning Z, Chen Y, Guo M, Liu Y, Gali NK, et al. Aerodynamic analysis of SARS-CoV-2 in two Wuhan hospitals. Nature. 2020;582(7813):557-60. https://doi.org/10.1038/s41586020-2271-3

38. Le T, Wang Y, Liu L, Yang J, Yung YL, Li G, et al. Unexpected air pollution with marked emission reductions during the COVID-19 outbreak in China. Science. 2020;369(6504):702-6. https://doi.org/ 10.1126/science.abb7431

39. Li H, Xu XL, Dai DW, Huang ZY, Ma Z, Guan YJ. Air pollution and temperature are associated with increased COVID-19 incidence: a time series study. Int J Infect Dis. 2020;97:278-82. https://doi.org/10.1016/j.ijid.2020.05.076.

40. Wu X, Nethery CR, Sabath MB. Exposure to air pollution and COVID-19 mortality in the United States.MedRxiv, 2020 https:// doi.org/10.1101/2020040520054502.

41. Tellier R. Aerosol transmission of influenza A virus: a review of new studies. J R Soc Interface. 2009;6(Suppl 6):S783-90. https:// doi.org/10.1098/rsif.2009.0302.focus.

42. Zhao R, Guo Z, Zhang R, Deng C, Xu J, Dong W, et al. Nasal epithelial barrier disruption by particulate matter mum via tight junction protein degradation. J Appl Toxicol. 2018;38(5):678-87. https://doi.org/10.1002/jat.3573.

Publisher's note Springer Nature remains neutral with regard to jurisdictional claims in published maps and institutional affiliations.

Springer Nature or its licensor holds exclusive rights to this article under a publishing agreement with the author(s) or other rightsholder(s); author self-archiving of the accepted manuscript version of this article is solely governed by the terms of such publishing agreement and applicable law. 